\title{
Metabolic regulation by secreted phospholipase $\mathrm{A}_{2}$
}

\author{
Hiroyasu Sato ${ }^{1}$, Yoshitaka Taketomi ${ }^{1}$ and Makoto Murakami ${ }^{1,2^{*}}$
}

\begin{abstract}
Within the phospholipase $A_{2}\left(P L A_{2}\right)$ superfamily that hydrolyzes phospholipids to yield fatty acids and lysophospholipids, the secreted PLA $\left(S P L A_{2}\right)$ enzymes comprise the largest family that contains 11 isoforms in mammals. Individual $\mathrm{SPLA}_{2} \mathrm{~s}$ exhibit unique distributions and specific enzymatic properties, suggesting their distinct biological roles. While $s P L A_{2} s$ have long been implicated in inflammation and atherosclerosis, it has become evident that they are involved in diverse biological events through lipid mediator-dependent or mediator-independent processes in a given microenvironment. In recent years, new biological aspects of sPLA $\mathrm{A}_{2}$ have been revealed using their transgenic and knockout mouse models in combination with mass spectrometric lipidomics to unveil their target substrates and products in vivo. In this review, we summarize our current knowledge of the roles of sPLA ${ }_{2} \mathrm{~s}$ in metabolic disorders including obesity, hepatic steatosis, diabetes, insulin resistance, and adipose tissue inflammation.
\end{abstract}

Keywords: Fatty acid, Lipoprotein, Obesity, Phospholipid, Phospholipase $A_{2}$

\section{Background}

Phospholipase $\mathrm{A}_{2}\left(\mathrm{PLA}_{2}\right)$ is a group of enzymes that hydrolyze phospholipids to yield fatty acids and lysophospholipids (Fig. 1). In general, this reaction is best known as the initial, rate-limiting step of arachidonate metabolism leading to the production of bioactive lipid mediators including prostaglandins and leukotrienes. The mammalian genome encodes more than $30 \mathrm{PLA}_{2} \mathrm{~S}$ or related enzymes, among which the secreted phospholipase $\mathrm{A}_{2}\left(\mathrm{sPLA}_{2}\right)$ family consists of low molecular mass and $\mathrm{Ca}^{2+}$-requiring enzymes with a conserved His-Asp catalytic dyad and includes 11 isoforms (IB, IIA, IIC, IID, IIE, IIF, III, V, X, XIIA, and XIIB) [1-5]. Beyond cytosolic PLA (cPLA $_{2} \alpha$; group IVA PLA ${ }_{2}$ ) whose regulatory roles in arachidonate metabolism have been well documented [6], the biological roles of $\mathrm{sPLA}_{2} \mathrm{~S}$ remained a mystery for more than two decades. Recent studies using mice that have been gene manipulated for $\mathrm{sPLA}_{2} \mathrm{~s}$ have begun to reveal their distinct and unique roles in various biological events [7-14]. The current understanding of the in vivo functions of $\mathrm{sPLA}_{2} \mathrm{~s}$ has been summarized in several reviews [1-5].

\footnotetext{
* Correspondence: murakami-mk@igakuken.or.jp

${ }^{1}$ Lipid Metabolism Project, The Tokyo Metropolitan Institute of Medical Science, 2-1-6 Kamikitazawa, Setagaya-ku, Tokyo 156-8506, Japan

${ }^{2}$ AMED-CREST, Japan Agency for Medical Research and Development, Tokyo 100-0004, Japan
}

(c) 2016 Sato et al. Open Access This article is distributed under the terms of the Creative Commons Attribution 4.0 International License (http://creativecommons.org/licenses/by/4.0/), which permits unrestricted use, distribution, and reproduction in any medium, provided you give appropriate credit to the original author(s) and the source, provide a link to the Creative Commons license, and indicate if changes were made. The Creative Commons Public Domain Dedication waiver (http://creativecommons.org/publicdomain/zero/1.0/) applies to the data made available in this article, unless otherwise stated.
Historically, sPLA 2 s have long been implicated in inflammation and atherosclerosis. This idea stems from the observations that sPLA 2 -IIA, a prototypic "inflammatory $\mathrm{SPLA}_{2}$," is induced during inflammation [15] and that hydrolysis of low-density lipoprotein (LDL) by sPLA ${ }_{2} \mathrm{~S}$ gives rise to pro-atherogenic LDL, which promotes macrophage foam cell formation in vitro [16, 17]. Indeed, subsequent genetic and pharmacological approaches support the proinflammatory or atherosclerotic roles of $\mathrm{SPLA}_{2} \mathrm{~S}$ [10-14]. However, the regulatory roles of $\mathrm{sPLA}_{2} \mathrm{~S}$ in metabolic disorders including obesity and insulin resistance have not yet been fully elucidated. Recently, it has become clear that several $\mathrm{SPLA}_{2} \mathrm{~S}$ are expressed in the adipose tissue or gastrointestinal (GI) tract and have variable influences on systemic metabolic states [18-20]. Here, we will make an overview of the novel biological roles of $\mathrm{SPLA}_{2} \mathrm{~S}$ and the lipid pathways underlying metabolic regulation, as revealed by sophisticated knockout and lipidomics techniques.

\section{$\mathrm{sPLA}_{2}-\mathrm{V}$, a "metabolic sPLA ${ }_{2}$ "}

Metabolic syndrome is increasing at an explosive rate worldwide due to a pandemic of obesity associated with diabetes, insulin resistance, non-alcoholic fatty liver disease, and hyperlipidemia [21]. The mechanisms connecting obesity to insulin resistance include an elevated level 


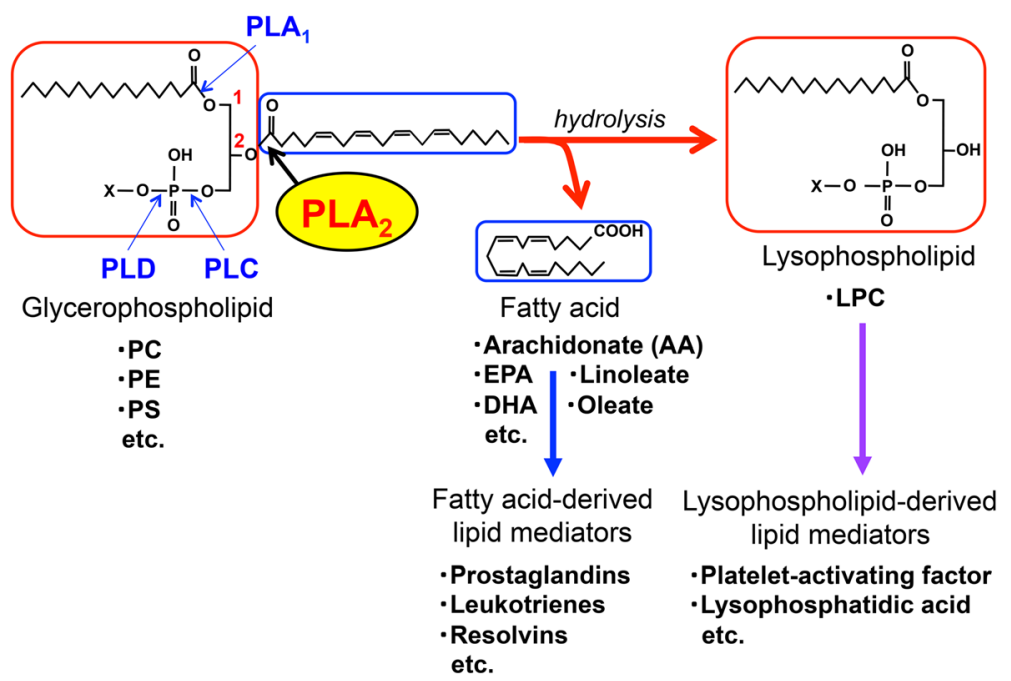

Fig. 1 PLA 2 reaction. PLA 2 hydrolyzes the $s n-2$ position of glycerophospholipids to yield fatty acids (typically unsaturated) and lysophospholipids. Phospholipases $A_{1}, C$, and D (PLA, PLC, and PLD, respectively) cleave other ester bonds in the glycerophospholipid molecule. Unsaturated fatty acids and lysophospholipids are further metabolized to a variety of lipid mediators

of circulating lipids, ectopic lipid deposition leading to lipotoxicity, and chronic inflammation in metabolically active tissues [22]. Obesity arises through the dysregulations of intracellular lipid metabolism or extracellular lipid partitioning among tissues, and the perturbation of intracellular/extracellular lipases variably and often profoundly affect obesity and insulin resistance [23-26]. For instance, lipoprotein lipase is an obesity susceptibility factor showing an inverse relationship between its activity and obesity-related traits in humans [23]. The imbalanced accumulation of LDL in favor of high-density lipoprotein (HDL) is a critical risk factor not only for atherosclerosis but also for insulin intolerance [27]. As lipoprotein particles are shielded by phospholipids, aberrant lipoprotein phospholipid metabolism could also influence lipid partitioning and thereby obesity.

Among the sPLA $\mathrm{S}_{2}$ isoforms, $\mathrm{sPLA}_{2}-\mathrm{V}$ potently hydrolyzes phospholipids in lipoproteins (LDL > HDL) in vitro [17]. However, studies using Pla2g $5^{-1-}$ mice have failed to demonstrate the participation of $s \mathrm{SLA}_{2}-\mathrm{V}$ in LDL metabolism in atherosclerosis models $[11,28]$. Except for studies using $\mathrm{sPLA}_{2}$-overexpressing transgenic mice $[17,29,30]$, no reports have firmly established whether endogenous $\mathrm{SPLA}_{2} \mathrm{~S}$ affect lipoprotein metabolism in vivo. In a microarray search for unique lipase-related genes whose expressions are associated with obesity, we recently found that $\mathrm{SPA}_{2}-\mathrm{V}$ (and SPLA $\mathrm{A}_{2}$-IIE; see below) is robustly induced in adipocytes of obese mice [18]. This $\operatorname{sPLA}_{2}-\mathrm{V}$ induction is dependent on adipogenesis plus endoplasmic reticulum (ER) stress. Because of this property plus the fact that $\mathrm{sPLA}_{2}-\mathrm{V}$ is constitutively expressed at relatively high levels in several metabolic tissues such as the heart and skeletal muscle, we refer to $\mathrm{SPLA}_{2}-\mathrm{V}$ as a "metabolic sPLA ${ }_{2}$."
Notably, when fed a high-fat diet (HFD), Pla2g5 $5^{-/-}$mice display hyperlipidemia with higher plasma levels of LDL, increased obesity and hepatic steatosis, and lower insulin sensitivity [18]. Furthermore, the adipose tissues in Pla $2 \mathrm{~g}^{-/-}$mice show a greater infiltration of M1 macrophages and a higher expression of pro-inflammatory cytokines. Thus, $\mathrm{SPLA}_{2}-\mathrm{V}$ plays anti-obesity and antiinflammatory roles in the context of metabolic disorders. Lipidomics have revealed that $\mathrm{sPLA}_{2}-\mathrm{V}$ secreted from hypertrophic adipocytes preferentially hydrolyzes phosphatidylcholine (PC) in fat-overladen LDL to release unsaturated fatty acids (e.g., oleate and linoleate) in vivo [18]. As such, the increased LDL lipid levels in Pla2g $5^{-1-}$ mice could impact on adipocyte hypertrophy and the fatty liver. Furthermore, in accordance with the alterations in LDL phospholipids, the levels of free oleate and linoleate are lower in the adipose tissue of HFDfed Pla2g5 $5^{-/-}$mice than in that of WT mice. These unsaturated fatty acids released by $\mathrm{SPLA}_{2}-\mathrm{V}$ dampen the M1 macrophage polarization by saturated fatty acids (e.g., palmitate) likely through the attenuation of ER stress. This mechanism fits with the view that $\mathrm{SPLA}_{2}-\mathrm{V}$ has an apparent, even if not strict, substrate preference for PC bearing a fatty acid with a low degree of unsaturation.

It remains obscure whether the $\mathrm{SPLA}_{2}-\mathrm{V}$ action would depend on the production of $\omega 6$ arachidonic acid-derived eicosanoids (e.g., prostaglandins and leukotrienes) or $\omega 3$ polyunsaturated fatty acid (e.g., eicosapentaenoic acid and docosahexaenoic acid)-derived pro-resolving lipid mediators (e.g., resolvins and protectins), since the adipose tissue levels of these fatty acid metabolites were not affected by Pla2g5 deficiency. Rather, $\mathrm{SPLA}_{2}-\mathrm{V}$ contributes to 
controlling the quality of the lipids, i.e., the balance between saturated (detrimental) and unsaturated (beneficial) fatty acids, in adipose tissue microenvironments, providing a novel insight into the sPLA 2 action beyond lipid mediators. Together, these results reveal a functional link between lipoprotein metabolism and anti-inflammation for this particular sPLA $\mathrm{A}_{2}$ and provide a rationale for the long-standing issue of the physiological importance of lipoprotein hydrolysis by this extracellular enzyme family (Fig. 2).

Another intriguing feature of $\mathrm{sPA}_{2}-\mathrm{V}$ is that it is a "Th2/M2-prone sPLA 2 ", allowing a shift in the immune balance toward the Th2/M2 status. Apart from the crucial role of adipocyte- rather than macrophage-derived $\mathrm{sPLA}_{2}$ $\mathrm{V}$ in obesity, the Pla2g5 expression in macrophages is markedly induced by the M2-skewing Th2 cytokines IL-4 and IL-13 and the Pla2g5 ablation decreases the Th2mediated immune responses $[18,31]$. In vitro, exogenous $\mathrm{SPLA}_{2}-\mathrm{V}$ is capable of facilitating the M2 polarization of macrophages probably through augmenting the prostaglandin $E_{2}$ production [18]. Furthermore, in human macrophages, $\mathrm{sPLA}_{2}-\mathrm{V}$ induced by $\mathrm{IL}-4$ promotes phagocytosis through the production of lysophosphatidylethanolamine [32]. Given the increased incidence of metabolic disorders resulting from the genetic ablation of Th2 or M2 inducers (e.g., Il4, Il13, Il33, Stat6, or Pparg) [33], the decreased whole-body Th2/M2 status resulting from Pla2g5 deficiency may also contribute to the exacerbation of obesityassociated inflammation. This notion also accords with the observations that Pla2 $g 5^{-/-}$mice are protected from asthma (Th2 dependent) [31], while suffering from more severe fungal infection (Th1 dependent) or arthritis (Th17 dependent) [10, 34], where the Th2 immunity counteracts the Th1/Th17-based inflammations. Thus, the fact that sPLA $_{2}-\mathrm{V}$ acts as a Th2/M2-prone sPLA 2 can account for the pro- versus anti-inflammatory actions of this enzyme in distinct immunopathological settings (Fig. 3).

Notably, in humans, Pla2g5 gene polymorphisms correlate with the LDL levels in subjects with type 2 diabetes or obesity $[35,36]$. The in vitro $\mathrm{sPLA}_{2}-\mathrm{V}$ susceptibility of LDL from patients with type 2 diabetes is greater than that of LDL from healthy controls [37]. Moreover, the Pla2g5 expression in the human visceral adipose tissue inversely correlates with LDL plasma levels [18]. These results imply a human relevance for the metabolic role of $\mathrm{SPLA}_{2}-\mathrm{V}$.

\section{sPLA - -IIE, another "metabolic sPLA 2 "}

We also found that SPLA $_{2}$-IIE, which remained a functionally orphan $\mathrm{SPLA}_{2}$ for more than a decade, acts as another "metabolic" sPLA $\mathrm{A}_{2}$ that is induced in hypertrophic adipocytes [18]. An adipogenic stimulus is sufficient for induction of sPLA $\mathrm{A}_{2}$-IIE in adipocytes. Pla $2 g 2 e^{-/-}$mice are modestly protected from diet-induced obesity, hepatic steatosis, and hyperlipidemia. In contrast to $\mathrm{sPLA}_{2}-\mathrm{V}$, which hydrolyzes $\mathrm{PC}$ in LDL to selectively release oleate and linoleate (see above), sPLA $\mathrm{A}_{2}$-IIE preferentially hydrolyzes minor lipoprotein phospholipids, phosphatidylserine (PS), and phosphatidylethanolamine (PE), with no appar-

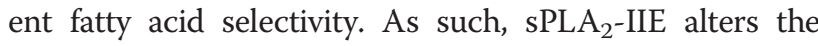
lipid composition of lipoproteins, thereby moderately affecting the lipid accumulation in the adipose tissue and liver.

Although the molecular mechanism that links lipoprotein PS/PE hydrolysis with obesity still remains unclear, this study revealed for the first time the importance of

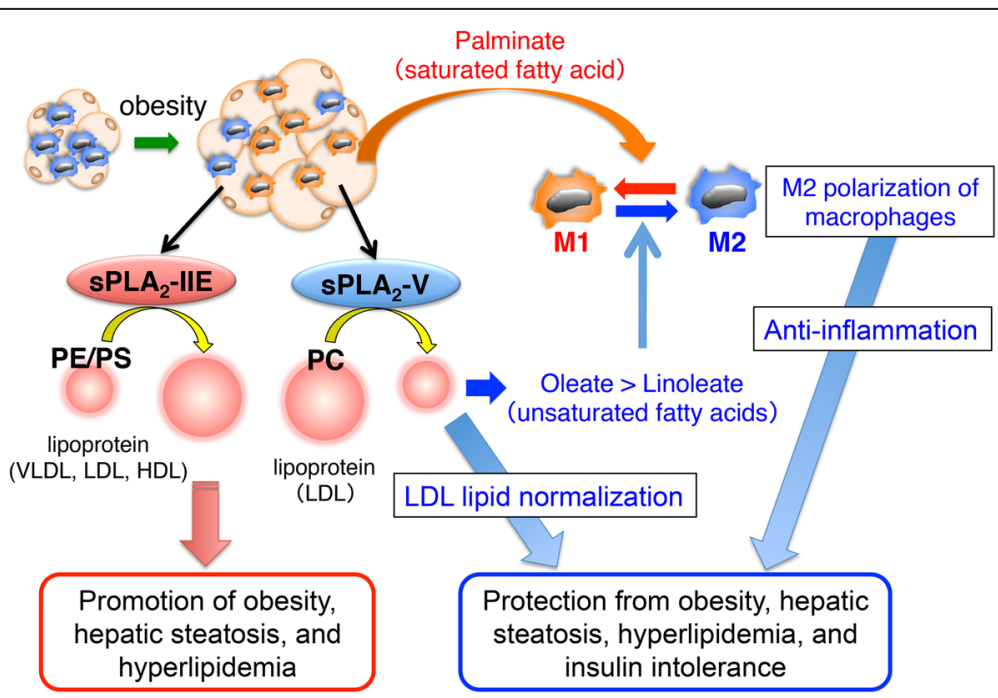

Fig. 2 Metabolic regulation by "metabolic $S P L A_{2} S$." During obesity, two $S P L A_{2} S$ (IIE and $V$ ) are induced in hypertrophic adipocytes. $S P L A_{2}-\| E$ hydrolyzes PE and PS in lipoproteins (VLDL, LDL, and HDL) and facilitates fat accumulation into the peripheral tissues. SPLA $-V$ hydrolyzes PC in LDL to release oleate and linoleate, which counteracts the palmitate-induced M1 polarization of macrophages and thereby sequesters adipose tissue inflammation [18] 


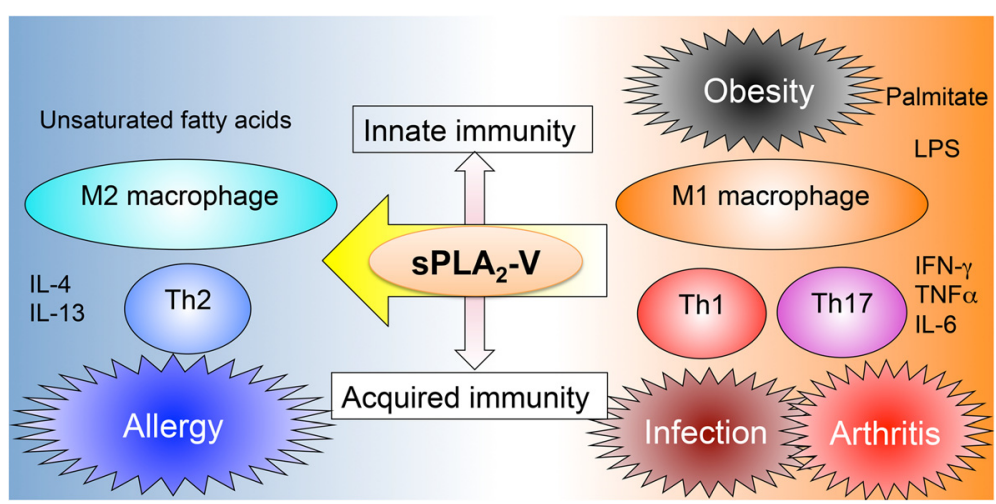

Fig. 3 Immune balance regulation by sPLA $-V$. sPLA $-V$ is induced in the M2 macrophages and Th2 cells by IL-4 or IL-13 and promotes Th2/M2-dominant immunity such as asthma [31, 32]. Conversely, SPLA $-V$ plays protective roles in Th1- or Th17-type immune responses including obesity, infection, and arthritis $[10,18,34]$

these minor lipoprotein phospholipids in metabolic regulation. As the increase of the negative charges in lipoproteins by oxidative modification renders the particles smaller, the increase of the anionic phospholipids (e.g., PS) in lipoproteins by the absence of sPLA 2 -IIE may also afford a similar effect. Alternatively, lysophosphatidylethanolamine or lysophosphatidylserine produced by sPLA $A_{2}$-IIE might have some metabolic effects, a possibility that awaits future studies. Collectively, these results underscore the physiological relevance of lipoprotein hydrolysis by distinct $\mathrm{sPLA}_{2} \mathrm{~S}$ and highlight the importance of "metabolic sPLA $\mathrm{A}_{2} \mathrm{~s}$ " as the integrated regulators of metabolic responses (Fig. 2).

On the other hand, another study has recently reported that Pla2g2e $e^{-/-}$mice accumulate more epididymal fat as they age [38]. During adipogenesis, the genetic deletion or siRNA knockdown of sPLA $_{2}$-IIE increases the triglyceride in adipocytes, while its overexpression or exogenous addition facilitates lipolysis. Although the reason for the discrepancy between the two studies is unclear, it might have arisen from different experimental conditions (HFD versus chow diets or female versus male mice) in different animal facilities.

\section{sPLA 2 -IB, a "digestive sPLA ${ }_{2}$ "}

Systemic lipid metabolism is often affected by the digestion and absorption of dietary lipids in the GI tract. sPLA $_{2}-\mathrm{IB}$ is synthesized by pancreatic acinar cells, and after secretion as a zymogen into pancreatic juice, an $\mathrm{N}$ terminal propeptide of the inactive zymogen is cleaved by trypsin to yield an active enzyme in the duodenum. The hydrolysis of PC by sPLA $\mathrm{A}_{2}$ IB is greatly accelerated in the presence of a low concentration of detergent such as deoxycholate [39]. This property appears to be physiologically important since the digestion of dietary phospholipids by sPLA $\mathrm{A}_{2}$-IB occurs in the presence of bile acid in the GI tract.
Pla $2 \mathrm{~g} \mathrm{~b}^{-/-}$mice show resistance to obesity, lower plasma insulin and leptin levels, and improved glucose tolerance when fed a high-fat/carbohydrate diet [40]. These phenotypes of Pla2g1 $\mathrm{b}^{-/-}$mice are most likely due to a marked reduction in the hydrolysis of dietary and biliary PC and thereby in the production and absorption of lysophosphatidylcholine (LPC) in the GI tract. The increased intestinal absorption of LPC promotes postprandial hyperglycemia by inhibiting the glucose uptake by the liver and muscle, and accordingly, the absence of $\mathrm{SPLA}_{2}$-IB reduces the postprandial LPC levels, leading to improved insulin sensitivity and hepatic fatty acid oxidation [41, 42]. It is noteworthy that Pla $2 \mathrm{glb}^{-/-}$mice on a $\mathrm{Ldlr}^{-/-}$background are protected from body weight gain and atherosclerosis in response to a hypercaloric diet [43] and that the oral administration of the sPLA $\mathrm{A}_{2}$ inhibitor methyl indoxam along with a diabetogenic diet effectively suppresses diet-induced obesity and diabetes in mice likely through the prevention of the intestinal digestion of dietary and biliary PC by sPLA $\mathrm{A}_{2}$-IB [44]. In further support of these observations, pancreatic acinar cell-specific Pla2g1b-transgenic mice develop more severe obesity and insulin resistance [45]. These results suggest that the inhibition of $\mathrm{sPLA}_{2}-\mathrm{IB}$, a "digestive sPLA $_{2}$," may be an effective oral therapeutic option for the treatment of diet-induced obesity and diabetes.

\section{Complex and enigmatic roles of $\mathrm{SPLA}_{2}-\mathrm{X}$ in metabolism}

Lastly, we briefly summarize the possible metabolic roles of ${ }_{\text {SPLA }}-\mathrm{X}$, although details remain uncertain because of the fact that conflicting results have been obtained. Like sPLA $_{2}-\mathrm{IB}, \mathrm{sPLA}_{2}-\mathrm{X}$ also has an $\mathrm{N}$-terminal propeptide, and its proteolytic removal leads to the full activation of the enzyme. A series of studies have provided some insights into the functional link of $\mathrm{sPLA}_{2}$-X-released polyunsaturated fatty acids to lipid-sensing nuclear receptor signaling. Macrophages from $\mathrm{Pla}_{2} \mathrm{glO}^{-/-}$mice show an increased 
expression of the cholesterol efflux transporters ABCA1 and $A B C G 1$, and this effect appears to be dependent on the suppression of the liver $\mathrm{X}$ receptor (LXR) by sPLA $\mathrm{A}_{2}-\mathrm{X}$ released polyunsaturated fatty acids [46]. Moreover, the increased cholesterol content of the lipid rafts in Pla2g10 macrophages leads to significant reduction of endotoxininduced inflammation [47]. The sPLA ${ }_{2}$-X-dependent suppression of LXR can also occur in the adipose tissue, where Pla2g10 deficiency facilitates adipogenesis and obesity [48], and in the adrenal glands, where its deficiency promotes corticosteroidogenesis through the activation of steroidogenic acute regulatory protein [49]. In the latter case, pro$\mathrm{sPLA}_{2}-\mathrm{X}$ is proteolytically processed to a mature, active form by the protein convertases furin and PCSK6, which are induced by the adrenocorticotropic hormone, in adrenal cells [50]. However, as far as we have been able to examine, the Pla2g10 expression in mouse macrophages and the adipose tissue is very low, arguing against the above observations. Rather, we prefer the idea that $\mathrm{SPLA}_{2}-\mathrm{X}$ might be expressed in a limited subset of these cells or supplied from proximal or distal cells in a paracrine manner.

On the other hand, we have shown that $\mathrm{sPLA}_{2}-\mathrm{X}$ is expressed abundantly in GI-lining cells and participates in phospholipid digestion [19]. Accordingly, Pla2g10 ${ }^{-/-}$ mice display a reduced age-associated adiposity and improved insulin sensitivity in the skeletal muscle, likely through a mechanism reminiscent of that in $\operatorname{Pla} 2 g 1 b^{-/-}$ mice. Thus, the two "digestive $\operatorname{sPLA}_{2} \mathrm{~s}$ " (IB and X) may spatiotemporally control the hydrolysis of dietary and biliary phospholipids and thereby the absorption of their hydrolytic products, depending on the quantity and quality of the dietary and biliary fat input. As in the case of Pla2g2e $e^{-/-}$mice (see above), the opposite phenotypes of Pla $2 \mathrm{~g} \mathrm{O}^{-/-}$mice observed in different studies might have been due to differences in the experimental models or housing conditions employed, and further studies will be necessary to clarify more definitively the roles and mechanistic actions of $\mathrm{sPLA}_{2}-\mathrm{X}$ in metabolism.

It has been recently reported that the glucosestimulated insulin secretion by islet $\beta$ cells is augmented in Pla2g10 $10^{-1-}$ mice, underscoring a novel metabolic role of $\mathrm{sPLA}_{2}-\mathrm{X}$ [51]. Mechanistically, sPLA ${ }_{2}-\mathrm{X}$ negatively regulates insulin secretion by augmenting the cyclooxygenase2-dependent prostaglandin $E_{2}$ production. In this scenario, targeting $\mathrm{SPLA}_{2}-\mathrm{X}$ may be an effective therapeutic option for enhancing $\beta$ cell function in the treatment of diabetes.

\section{Conclusions}

It is now obvious that at least four sPLA $\mathrm{S}_{2} \mathrm{~s}$ are involved in metabolic regulation through distinct mechanisms, as summarized below. sPLA $\mathrm{A}_{2}-\mathrm{V}$ is induced in hypertrophic adipocytes by obesity-associated ER stress and hydrolyzes PC in hyperlipidemic LDL to facilitate the skewing of macrophages from M1 to M2 subsets, thereby conferring protection from adipose tissue inflammation, insulin resistance, obesity, hepatic steatosis, and hyperlipidemia. The saturated fatty acids supplied abundantly from adipocytes trigger the M1 polarization of macrophages, which is counterregulated by the $\mathrm{SPLA}_{2}-\mathrm{V}$-driven unsaturated fatty acids from LDL. SPLA 2 -IIE is induced in adipocytes in accordance with adipogenesis and hydrolyzes $\mathrm{PE}$ and PS in lipoproteins, eventually promoting fat storage in the adipose tissue and liver. $\mathrm{SPLA}_{2}-\mathrm{IB}$, a pancreatic $\mathrm{SPLA}_{2}$ that is secreted into the GI lumen, hydrolyzes dietary and biliary phospholipids to promote lipid digestion and absorption, which is associated with obesity and hepatic insulin resistance. $\mathrm{sPLA}_{2}-\mathrm{X}$ variably affects metabolism possibly through the production of polyunsaturated fatty acids that modify the LXR signaling in the adipose tissue, through the digestion of the dietary and biliary phospholipids in the gut, or through the generation of prostaglandin $E_{2}$ that suppresses insulin secretion in the pancreatic islet. In addition, sPLA $\mathrm{A}_{2}$-IIA is abundantly expressed in the human and rat adipose tissues in obesity and the pharmacological inhibition of this isoform attenuates the adipose tissue inflammation in rats $[18,52]$. It remains possible that other $\mathrm{sPLA}_{2}$ isoforms may also participate in metabolic regulation, and this issue is now under investigation. Together, these studies have brought about a paradigm shift toward a better understanding of the biological roles of this extracellular lipolytic enzyme family as coordinators of metabolism.

Competing interests

The authors declare that they have no competing interests.

Authors' contributions

$H S, Y T$, and MM wrote this review. All authors read and approved the final manuscript.

\section{Acknowledgments}

We thank Dr. A. Kumoanogoh (University of Osaka, Japan) for providing an opportunity to write this manuscript.

\section{Funding}

This work was supported by a grant-in-aid for scientific research from the Ministry of Education, Science, Culture, Sports and Technology of Japan and AMED-CREST from the Japan Agency for Medical Research and Development.

Received: 30 December 2015 Accepted: 10 May 2016

Published online: 21 May 2016

\section{References}

1. Lambeau G, Gelb MH. Biochemistry and physiology of mammalian secreted phospholipases A2. Annu Rev Biochem. 2008;77:495-520.

2. Murakami M, Taketomi Y, Girard C, Yamamoto K, Lambeau G. Emerging roles of secreted phospholipase $A_{2}$ enzymes: lessons from transgenic and knockout mice. Biochimie. 2010;92:561-82.

3. Dennis EA, Cao J, Hsu YH, Magrioti V, Kokotos G. Phospholipase $A_{2}$ enzymes: physical structure, biological function, disease implication, chemical inhibition, and therapeutic intervention. Chem Rev. 2011;111:6130-85.

4. Murakami M, Taketomi $Y$, Miki Y, Sato H, Hirabayashi T, Yamamoto K. Recent progress in phospholipase $A_{2}$ research: from cells to animals to humans. Prog Lipid Res. 2011;50:152-92.

5. Murakami M, Sato H, Miki Y, Yamamoto K, Taketomi $Y$. A new era of secreted phospholipase A. J Lipid Res. 2015;56:1248-61. 
6. Uozumi N, Kume K, Nagase T, Nakatani N, Ishii S, Tashiro F, et al. Role of cytosolic phospholipase $\mathrm{A}_{2}$ in allergic response and parturition. Nature. 1997;390:618-22.

7. Taketomi Y, Ueno N, Kojima T, Sato H, Murase R, Yamamoto K, et al. Mast cell maturation is driven via a group III phospholipase $\mathrm{A}_{2}$-prostaglandin $D_{2}$-DP1 receptor paracrine axis. Nat Immunol. 2013;14:554-63.

8. Sato $H$, Taketomi $Y$, Isogai $Y$, Miki $Y$, Yamamoto $K$, Masuda S, et al. Group III secreted phospholipase $A_{2}$ regulates epididymal sperm maturation and fertility in mice. J Clin Invest. 2010;120:1400-14.

9. Yamamoto K, Taketomi Y, Isogai Y, Miki Y, Sato H, Masuda S, et al. Hair follicular expression and function of group $X$ secreted phospholipase $A_{2}$ in mouse skin. J Biol Chem. 2011;286:11616-31.

10. Boilard E, Lai Y, Larabee K, Balestrieri B, Ghomashchi F, Fujioka D, et al. A novel anti-inflammatory role for secretory phospholipase $A_{2}$ in immune complex-mediated arthritis. EMBO Mol Med. 2010;2:172-87.

11. Bostrom MA, Boyanovsky BB, Jordan CT, Wadsworth MP, Taatjes DJ, de Beer FC, et al. Group $V$ secretory phospholipase $A_{2}$ promotes atherosclerosis: evidence from genetically altered mice. Arterioscler Thromb Vasc Biol. 2007;27:600-6.

12. Henderson Jr WR, Chi EY, Bollinger JG, Tien YT, Ye X, Castelli L, et al. Importance of group $X$-secreted phospholipase $A_{2}$ in allergen-induced airway inflammation and remodeling in a mouse asthma model. J Exp Med. 2007;204:865-77.

13. Muñoz NM, Meliton AY, Arm JP, Bonventre JV, Cho W, Leff AR. Deletion of secretory group $V$ phospholipase $A_{2}$ attenuates cell migration and airway hyperresponsiveness in immunosensitized mice. J Immunol. 2007;179:4800-7.

14. Yamamoto K, Miki Y, Sato M, Taketomi Y, Nishito Y, Taya C, et al. The role of group IIF-secreted phospholipase A2 in epidermal homeostasis and hyperplasia. J Exp Med. 2015;212:1901-19.

15. Seilhamer JJ, Pruzanski W, Vadas P, Plant S, Miller JA, Kloss J, et al. Cloning and recombinant expression of phospholipase $A_{2}$ present in rheumatoid arthritic synovial fluid. J Biol Chem. 1989;264:5335-8.

16. Hanasaki K, Yamada K, Yamamoto S, Ishimoto Y, Saiga A, Ono T, et al. Potent modification of low density lipoprotein by group $X$ secretory phospholipase $A_{2}$ is linked to macrophage foam cell formation. J Biol Chem. 2002:277:29116-24.

17. Sato H, Kato R, Isogai $Y$, Saka G, Ohtsuki M, Taketomi Y, et al. Analyses of group III secreted phospholipase $A_{2}$ transgenic mice reveal potential participation of this enzyme in plasma lipoprotein modification, macrophage foam cell formation, and atherosclerosis. J Biol Chem. 2008;283:33483-97.

18. Sato H, Taketomi Y, Ushida A, Isogai Y, Kojima T, Hirabayashi T, et al. The adipocyte-inducible secreted phospholipases PLA2G5 and PLA2G2E play distinct roles in obesity. Cell Metab. 2014;20:119-32.

19. Sato H, Isogai $Y$, Masuda S, Taketomi Y, Miki Y, Kamei D, et al. Physiological roles of group $X$-secreted phospholipase $A_{2}$ in reproduction, gastrointestinal phospholipid digestion, and neuronal function. J Biol Chem. 2011;286:11632-48.

20. Hui DY. Phospholipase $A_{2}$ enzymes in metabolic and cardiovascular diseases. Curr Opin Lipidol. 2012;23:235-40.

21. Despres JP, Lemieux I. Abdominal obesity and metabolic syndrome. Nature. 2006;444:881-7.

22. Hotamisligil GS. Inflammation and metabolic disorders. Nature. 2006:444:860-7.

23. Chen Y, Zhu J, Lum PY, Yang X, Pinto S, MacNeil DJ, et al. Variations in DNA elucidate molecular networks that cause disease. Nature. 2008;452:429-35

24. Chiu HK, Qian K, Ogimoto K, Morton GJ, Wisse BE, Agrawal N, et al. Mice lacking hepatic lipase are lean and protected against diet-induced obesity and hepatic steatosis. Endocrinology. 2010;151:993-1001.

25. Haemmerle G, Lass A, Zimmermann R, Gorkiewicz G, Meyer C, Rozman J, et al. Defective lipolysis and altered energy metabolism in mice lacking adipose triglyceride lipase. Science. 2006;312:734-7.

26. Wang $H$, Knaub LA, Jensen DR, Young Jung D, Hong EG, Ko HJ, et al. Skeletal muscle-specific deletion of lipoprotein lipase enhances insulin signaling in skeletal muscle but causes insulin resistance in liver and other tissues. Diabetes. 2009:58:116-24.

27. Avramoglu RK, Basciano H, Adeli K. Lipid and lipoprotein dysregulation in insulin resistant states. Clin Chim Acta. 2006:368:1-19.

28. Boyanovsky B, Zack M, Forrest $K$, Webb NR. The capacity of group $\vee s P L A_{2}$ to increase atherogenicity of $A p o E^{-/-}$and $L_{D L R^{-/-}}$mouse $L D L$ in vitro predicts its atherogenic role in vivo. Arterioscler Thromb Vasc Biol. 2009;29:532-8.

29. Ivandic B, Castellani LW, Wang XP, Qiao JH, Mehrabian M, Navab M, et al. Role of group II secretory phospholipase $A_{2}$ in atherosclerosis: 1. Increased atherogenesis and altered lipoproteins in transgenic mice expressing group Ila phospholipase A2. Arterioscler Thromb Vasc Biol. 1999;19:1284-90.
30. Yamamoto K, Isogai Y, Sato H, Taketomi Y, Murakami M. Secreted phospholipase $\mathrm{A}_{2}$ lipoprotein hydrolysis, and atherosclerosis: integration with lipidomics. Anal Bioanal Chem. 2011;400:1829-42.

31. Ohta S, Imamura M, Xing W, Boyce JA, Balestrieri B. Group V secretory phospholipase $A_{2}$ is involved in macrophage activation and is sufficient for macrophage effector functions in allergic pulmonary inflammation. J Immunol. 2013;190:5927-38.

32. Rubio JM, Rodríguez JP, Gil-de-Gómez L, Guijas C, Balboa MA, Balsinde J. Group V secreted phospholipase $A_{2}$ is upregulated by IL-4 in human macrophages and mediates phagocytosis via hydrolysis of ethanolamine phospholipids. J Immunol. 2015;194:3327-39.

33. Odegaard $\mathrm{Jl}$, Chawla A. The immune system as a sensor of the metabolic state. Immunity. 2013;38:644-54.

34. Balestrieri B, Maekawa A, Xing W, Gelb MH, Katz HR, Arm JP. Group V secretory phospholipase $A_{2}$ modulates phagosome maturation and regulates the innate immune response against Candida albicans. J Immunol 2009:182:4891-8.

35. Sergouniotis PI, Davidson AE, Mackay DS, Lenassi E, Li Z, Robson AG, et al. Biallelic mutations in PLA2G5, encoding group $V$ phospholipase $A_{2}$, cause benign fleck retina. Am J Hum Genet. 2011;89:782-91.

36. Wootton PT, Arora NL, Drenos F, Thompson SR, Cooper JA, Stephens JW, et al. Tagging SNP haplotype analysis of the secretory PLA $-V$ gene, PLA2G5, shows strong association with $L D L$ and oxLDL levels, suggesting functional distinction from SPLA $-\| A$ : results from the UDACS study. Hum Mol Genet. 2007; 16:1437-44.

37. Pettersson C, Fogelstrand L, Rosengren B, Stahlman S, Hurt-Camejo E, Fagerberg B, et al. Increased lipolysis by secretory phospholipase $A_{2}$ group $V$ of lipoproteins in diabetic dyslipidaemia. J Intern Med. 2008;264 155-65.

38. Zhi H, Qu L, Wu F, Chen L, Tao J. Group IIE secretory phospholipase A2 regulates lipolysis in adipocytes. Obesity (Silver Spring). 2015;23:760-8.

39. Jain MK, Egmond MR, Verheij HM, Apitz-Castro R, Dijkman R, De Haas GH. Interaction of phospholipase $A_{2}$ and phospholipid bilayers. Biochim Biophys Acta. 1982:688:341-8.

40. Huggins KW, Boileau AC, Hui DY. Protection against diet-induced obesity and obesity-related insulin resistance in Group 1B PLA ${ }_{2}$-deficient mice. Am J Physiol Endocrinol Metab. 2002;283:E994-E1001.

41. Labonté ED, Kirby RJ, Schildmeyer NM, Cannon AM, Huggins KW, Hui DY. Group 1B phospholipase $\mathrm{A}_{2}$-mediated lysophospholipid absorption directly contributes to postprandial hyperglycemia. Diabetes. 2006;55:935-41.

42. Labonté ED, Pfluger PT, Cash JG, Kuhel DG, Roja JC, Magness DP, et al. Postprandial lysophospholipid suppresses hepatic fatty acid oxidation: the molecular link between group 1B phospholipase $\mathrm{A}_{2}$ and diet-induced obesity. FASEB J. 2010;24:2516-24.

43. Hollie NI, Konaniah ES, Goodin C, Hui DY. Group 1B phospholipase $A_{2}$ inactivation suppresses atherosclerosis and metabolic diseases in LDL receptor-deficient mice. Atherosclerosis. 2014:234:377-80.

44. Hui DY, Cope MJ, Labonté ED, Chang HT, Shao J, Goka E, et al. The phospholipase $A_{2}$ inhibitor methyl indoxam suppresses diet-induced obesity and glucose intolerance in mice. Br J Pharmacol. 2009;157:1263-9.

45. Cash JG, Kuhel DG, Goodin C, Hui DY. Pancreatic acinar cell-specific overexpression of group 1B phospholipase $A_{2}$ exacerbates diet-induced obesity and insulin resistance in mice. Int J Obes (Lond). 2011:35:877-81.

46. Shridas P, Bailey WM, Gizard F, Oslund RC, Gelb MH, Bruemmer D, et al. Group $X$ secretory phospholipase $A_{2}$ negatively regulates $A B C A 1$ and ABCG1 expression and cholesterol efflux in macrophages. Arterioscler Thromb Vasc Biol. 2010;30:2014-21.

47. Shridas P, Bailey WM, Talbott KR, Oslund RC, Gelb MH, Webb NR. Group X secretory phospholipase $A_{2}$ enhances TLR4 signaling in macrophages. J Immunol. 2011;187:482-9.

48. Li X, Shridas P, Forrest K, Bailey W, Webb NR. Group X secretory phospholipase $A_{2}$ negatively regulates adipogenesis in murine models. FASEB J. 2010;24:4313-24.

49. Shridas P, Bailey WM, Boyanovsky BB, Oslund RC, Gelb MH, Webb NR. Group $X$ secretory phospholipase $A_{2}$ regulates the expression of steroidogenic acute regulatory protein (StAR) in mouse adrenal glands. J Biol Chem. 2010; 285:20031-9.

50. Layne JD, Shridas P, Webb NR. Ectopically expressed pro-group X secretory phospholipase $A_{2}$ is proteolytically activated in mouse adrenal cells by furin-like proprotein convertases: implications for the regulation of adrenal steroidogenesis. J Biol Chem. 2015;290:7851-60. 
51. Shridas P, Zahoor L, Forrest KJ, Layne JD, Webb NR. Group X secretory phospholipase $\mathrm{A}_{2}$ regulates insulin secretion through a cyclooxygenase-2dependent mechanism. J Biol Chem. 2014;289(40):27410-7.

52. Iyer A, Lim J, Poudyal H, Reid RC, Suen JY, Webster J, et al. An inhibitor of phospholipase $\mathrm{A}_{2}$ group IIA modulates adipocyte signaling and protects against diet-induced metabolic syndrome in rats. Diabetes. 2012;61:2320-9.

Submit your next manuscript to BioMed Central and we will help you at every step:

- We accept pre-submission inquiries

- Our selector tool helps you to find the most relevant journal

- We provide round the clock customer support

- Convenient online submission

- Thorough peer review

- Inclusion in PubMed and all major indexing services

- Maximum visibility for your research

Submit your manuscript at www.biomedcentral.com/submit 